\title{
Erratum to: Timing continuous or discontinuous movements across effectors specified by different pacing modalities and intervals
}

\author{
H. Lorås · H. Sigmundsson · J. B. Talcott • \\ F. Öhberg $\cdot$ A. K. Stensdotter
}

Published online: 27 November 2012

(c) Springer-Verlag Berlin Heidelberg 2012

Erratum to: Exp Brain Res (2012) 220:335-347

DOI 10.1007/s00221-012-3142-4

In the original publication of this article, an incorrectly processed set of the data was displayed in Fig. 3a-j. The correct figure with its legend is as follows:

The online version of the original article can be found under doi:10.1007/s00221-012-3142-4.

H. Lorås $(\bowtie) \cdot$ H. Sigmundsson · A. K. Stensdotter Faculty of Health Education and Social Work,

Division Physiotherapy, Sør-Trøndelag University College,

7004 Trondheim, Norway

e-mail: havard.loras@hist.no

H. Lorås · H. Sigmundsson

Research Group for Learning and Skill Development,

Department of Psychology, Norwegian University of Science

and Technology, Trondheim, Norway

J. B. Talcott

Aston Brain Centre, School of Life and Health Sciences,

Aston University, Birmingham, UK

F. Öhberg

Department of Biomedical Engineering and Informatics,

Radiation Science, Umeå University, Umeå, Sweden 
Fig. 3 Within-trial

synchronization error means

(a, b), means in absolute values

(c, d), standard deviations (e, f), coefficient of variations $(\mathbf{g}, \mathbf{h})$ and lag one autocorrelations $(\mathbf{i}, \mathbf{j})$ averaged across all 100 participants in all experimental conditions. Error bars denote standard errors. Filled square dominant hand; filled circle non-dominant hand; solid line auditory pacing; dashed line visual pacing
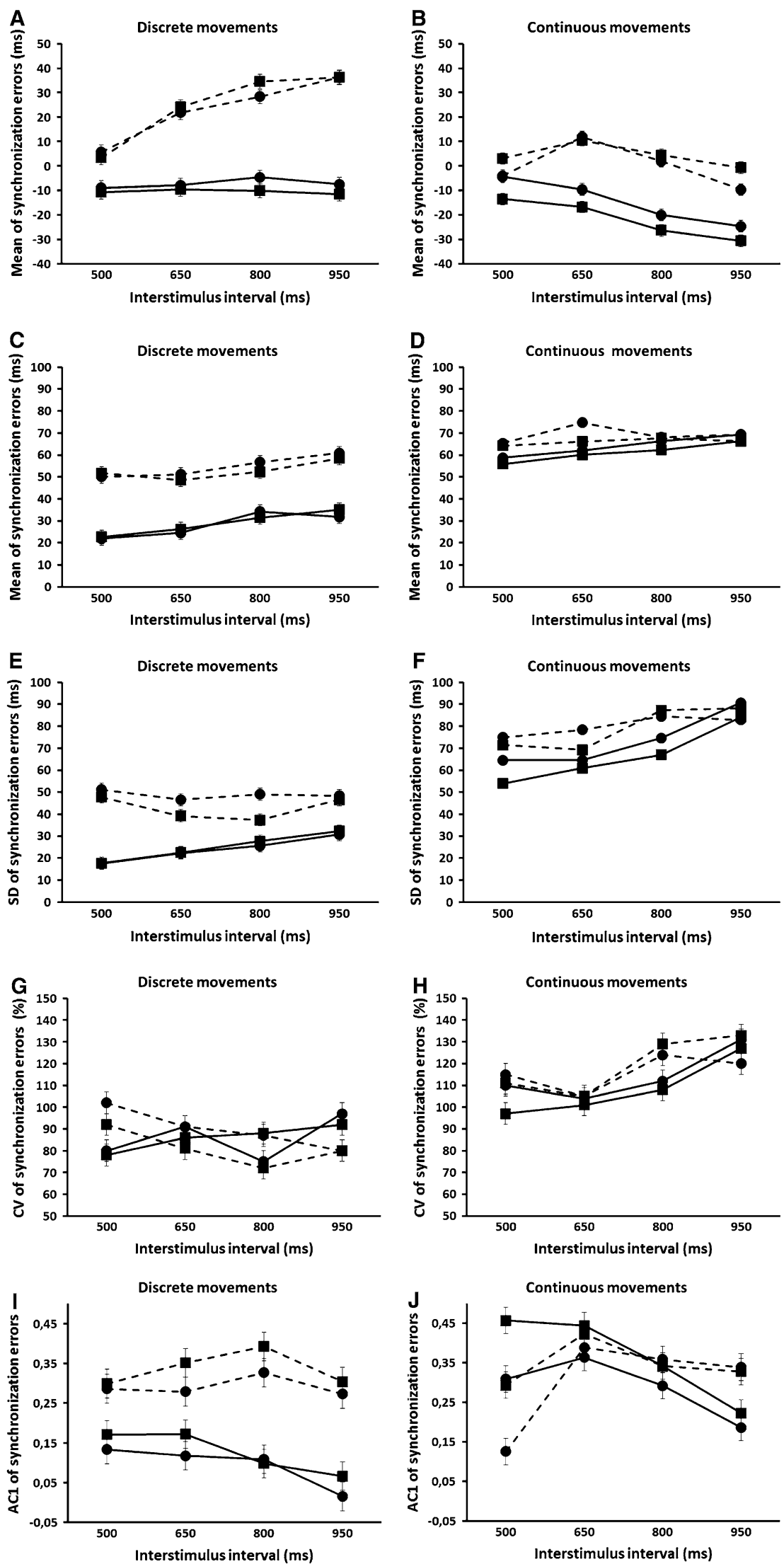